\title{
Application of Magnetic Levitation Induced Weightlessness to Detect Cell Lineage
}

\author{
Oyku Sarigil \\ Department of Bioengineering \\ Izmir Institute of Technology \\ Izmir, Turkey \\ ORCID: 0000-0002-1207-1653 \\ Melike Cagan \\ Department of Bioengineering \\ Izmir Institute of Technology \\ Izmir, Turkey \\ ORCID: 0000-0002-0616-6488
}

\author{
Muge Anil-Inevi \\ Department of Bioengineering \\ Izmir Institute of Technology \\ Izmir, Turkey \\ ORCID: 0000-0003-2854-3472 \\ Gulistan Mese \\ Department of Molecular Biology \\ and Genetics \\ Izmir Institute of Technology \\ Izmir, Turkey \\ ORCID: 0000-0003-0458-8684 \\ Engin Ozcivici \\ Department of Bioengineering \\ Izmir Institute of Technology \\ Izmir, Turkey \\ ORCID: 0000-0003-4464-0475
}

\author{
Esra Yilmaz \\ Department of Bioengineering \\ Izmir Institute of Technology \\ Izmir, Turkey \\ ORCID: 0000-0002-5758-5439 \\ H. Cumhur Tekin \\ Department of Bioengineering \\ Izmir Institute of Technology \\ Izmir, Turkey \\ ORCID: 0000-0002-5758-5439
}

\begin{abstract}
Identification and classification of bone marrow cells is an important step for molecular biology and therapeutic studies related to bone marrow disorders such as osteoporosis or obesity. In this study, we applied magnetic levitation technology to induce a weightlessness environment to detect adipocytes and osteoblasts based on their single cell density. This biotechnological method can be used for separation of heterogeneous populations such as bone marrow once adapted to a continuous microfluidic platform.
\end{abstract}

Keywords - magnetic levitation, bone marrow stem cells, adipocytes, osteoblasts, cell detection

\section{INTRODUCTION}

Bone marrow stem cells have the capability of differentiation into adipocytes and osteoblasts [1]. It had been demonstrated in previous studies there was a negative relationship between bone marrow adipogenesis and osteoblastogenesis $[2,3]$. The shift of balance between these two processes may affect bone health and hematopoiesis, and cause inhibition at bone reformation [4-6]. The density of the cells changes during differentiation process and it can be utilized as an indicator of cell state [7]. Magnetic levitation is a density-based technique which simulates weightlessness environment by using diamagnetic properties of cells $[7,8]$. In this weightlessness environment induced by the magnetic field, cells position themselves in the field gradient based on their density. Here, we used a magnetic levitation device for density-based cell detection of differentiated adipogenic and osteogenic cells.

\section{METHODS}

Magnetic levitation device is composed of two permanent magnets with same poles facing each other to create a magnetic force, a capillary channel to load cells and two mirrors placed at $45^{\circ}$ for real-time imaging of cell position (Fig. 1A). These parts were held together with $3 \mathrm{D}$ printed polymeric construct [9].

Financial support: Scientific and Technological Research Council of Turkey (215S862- EO, 116M298 - HCT) and Turkish Academy of Sciences (Young Investigator Award - EO).
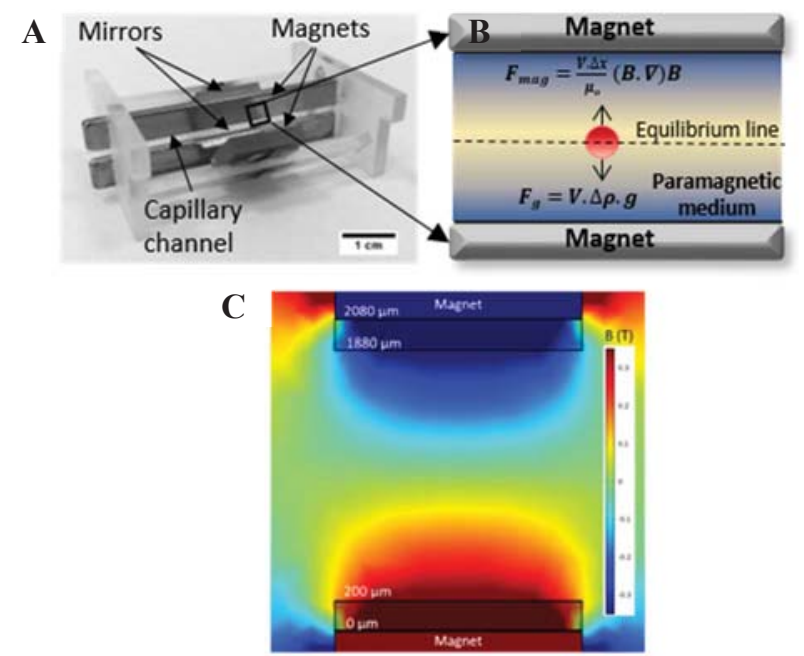

Fig. 1. Magnetic levitation setup and working principle. (A) Magnetic levitation device. Scale bar: $1 \mathrm{~cm}$. (B) Main forces on cells in magnetic levitation. (C) Representation of magnetic induction between two magnets. Center of the gap between magnets has minimum magnetic field.

In the levitation device, two main forces occur; magnetic force $\left(\mathrm{F}_{\mathrm{mag}}\right)$ where $V$ is cell volume, $\Delta \chi$ is magnetic susceptibility difference between paramagnetic medium and cell, $\mu_{0}$ is permeability of free space, $B$ is magnetic induction (Eq. 1), and corrected gravitational force $\left(\mathrm{F}_{\mathrm{g}}\right.$, combination of gravitational force and buoyancy force) where $\Delta \rho$ is density difference between paramagnetic medium and cell, $g$ is gravitational acceleration (Eq. 2). When these forces are balanced, the cells are located according to their density in the capillary (Fig. 1B). One of the strategies for increasing response of diamagnetic cells to magnetic force is to use a

$$
\begin{gathered}
F_{m a g}=\frac{V \cdot \Delta \chi}{\mu_{0}}(B \cdot \nabla) B \\
F_{g}=V \cdot \Delta \rho \cdot g
\end{gathered}
$$


paramagnetic medium. Thereby, magnetic susceptibility difference increases and the cells move to lower magnetic induction field (Fig. 1C).

Before levitation of the cells, the levitation system was calibrated with polymeric beads with known density using 25 $\mathrm{mM}$ Gadavist $\left(\mathrm{Gd}^{3+}\right)$ as paramagnetic agent and it was obtained a linear equation to measure the density of the cells from their levitation height. Then, D1 ORL UVA cells (bone marrow stem cell) were grown in basal medium and 7F2 (osteoblast) cells were differentiated in adipogenic over 10 days and osteogenic medium over 14 days with inducing agents, and differentiated cells were stained with oil red o and alizarin red to test oil and mineral accumulation, respectively (Fig. 2). After differentiation, the cells were trypsinized and levitated with concentration of 5000 cells/capillary in medium containing $25 \mathrm{mM} \mathrm{Gd}^{3+}$ (Fig. 3A).

\section{RESULTS AND DISCUSSION}

In this study, we aimed to use magnetic levitation system, which eliminates the need of time-consuming cell labeling steps [10], as a detection tool for differentiation of the cells. Therefore, D1 ORL UVA cells [11] were grown in basal media, whereas 7F2 cells were cultured in adipogenic media and in osteogenic induction media. Stem cells, adipogenic differentiated cells and osteogenic differentiated cells were levitated using paramagnetic media. The levitated stem cells were located in a straight line in the levitation device. On the other hand, adipogenic cells were mostly positioned at higher levitation heights and osteogenic cells showed wide distribution compared to stem cells in the capillary (Fig. 3A).

Undifferentiated D1 ORL UVA cells had average density of $1.069 \pm 0.006 \mathrm{~g} / \mathrm{mL}$. It was seen the adipogenic differentiated cells expanded in two directions, however, upper part was $46 \%$ with average density of $1.079 \pm 0.016$ $\mathrm{g} / \mathrm{mL}$ and lower part were $54 \%$ with average density of 1.037 $\pm 0.018 \mathrm{~g} / \mathrm{mL}$ in all population where the cells were separated from density of $1.06 \mathrm{~g} / \mathrm{mL}$. Also, osteogenic differentiated cells were $41 \%(1.076 \pm 0.012 \mathrm{~g} / \mathrm{mL})$ at upper part and $59 \%$ $(1.047 \pm 0.008 \mathrm{~g} / \mathrm{mL})$ at lower part (Fig. 3B).

When the cells were classified with respect to density distribution, it was observed that the stem cells, adipocytes and osteoblasts showed different patterns in levitation system (Fig. 3C). $65 \%$ of stem cells had density of $1.07 \mathrm{~g} / \mathrm{mL}$, however, the most of adipogenic and osteogenic cells had density of $1.05 \mathrm{~g} / \mathrm{mL}$. Also, single cell density decreased to as low as $0.98 \mathrm{~g} / \mathrm{mL}$ for adipogenic cells whereas no such decrease in osteogenic cells. According to this preliminary

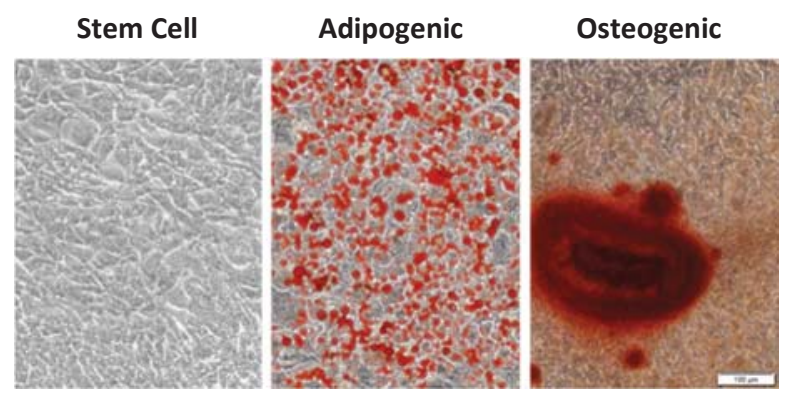

Fig. 2. Culture images of D1 ORL UVA and 7F2 cells. 7F2 cells were stained with oil red o and alizarin red after adipogenic and osteogenic differentiation, respectively. Scale bar: $100 \mu \mathrm{m}$.
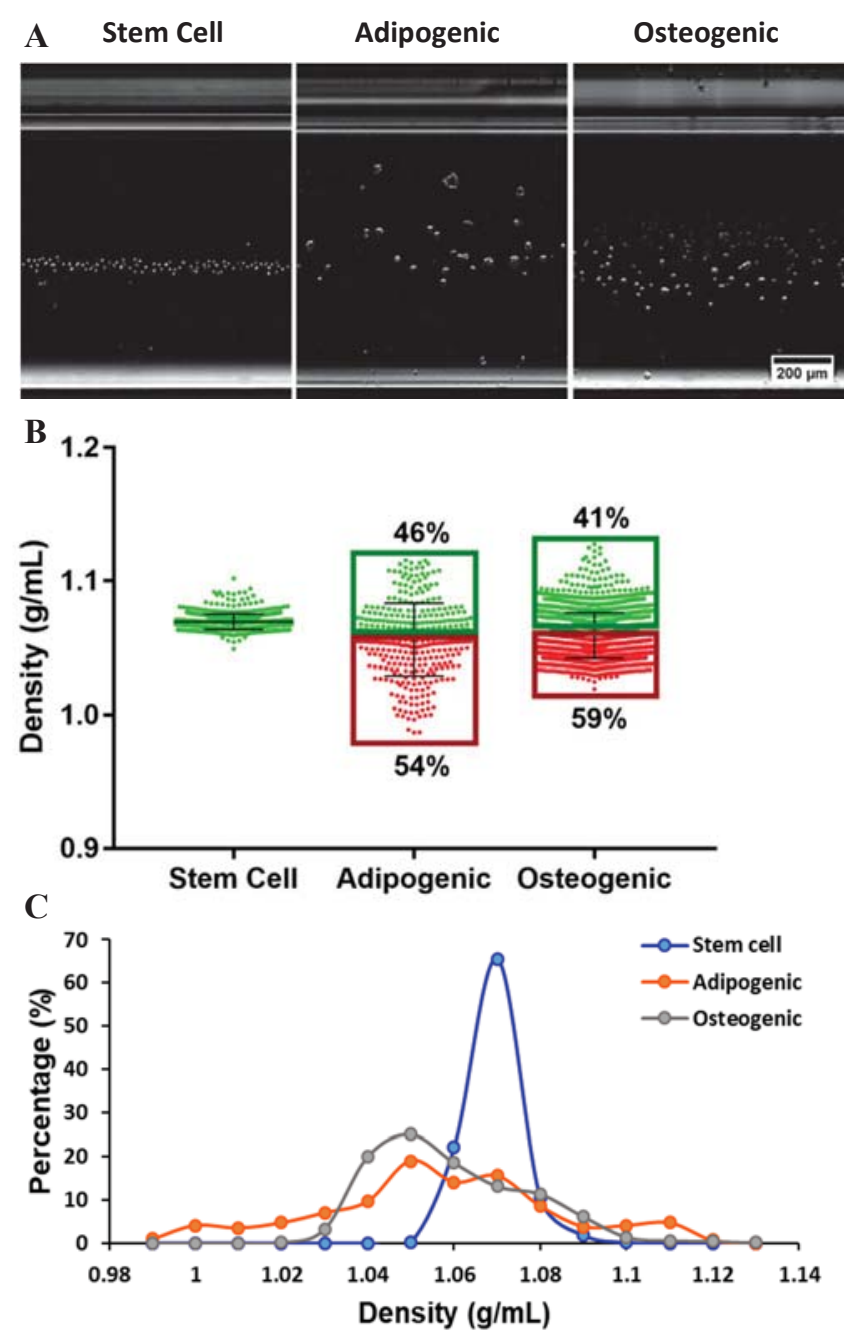

Fig. 3. (A) Levitation images of undifferentiated D1 and adipogenic and osteogenic differentiated 7F2 cells in medium with $25 \mathrm{mM} \mathrm{Gd}^{3+}$. Scale bar: $200 \mu \mathrm{m}$ (B) Scatter plot of densities of stem cells, adipogenic cells and osteogenic cells. (C) Density distribution of three cell types.

studies, it could be possible to distinguish these three different cell types [12].

\section{CONCLUSIONS}

The technique established here offers density-based detection to distinguish stem cells from differentiated cells with the advantage of real-time imaging. It can be possible to use this system as diagnostic tools for diseases that exhibit cellular density alterations due to abnormal adipogenesis and osteoblastogenesis processes. Also, the system can provide cell separation by modifying because of microfluidic nature and thereby it can be possible to research differentiated cells in a molecular level.

\section{REFERENCES}

[1] Q. Chen et al., "Fate decision of mesenchymal stem cells: adipocytes or osteoblasts?," Cell death and differentiation, vol. 23, no. 7, p. 1128, 2016.

[2] B. M. Abdallah, "Marrow adipocytes inhibit the differentiation of mesenchymal stem cells into osteoblasts via suppressing BMPsignaling," Journal of biomedical science, vol. 24, no. 1, p. 11, 2017. 
[3] S. Muruganandan, A. Roman, and C. Sinal, "Adipocyte differentiation of bone marrow-derived mesenchymal stem cells: cross talk with the osteoblastogenic program," Cellular molecular life sciences, vol. 66, no. 2, pp. 236-253, 2009.

[4] S. Muruganandan, R. Govindarajan, and C. J. Sinal, "Bone marrow adipose tissue and skeletal health," Current osteoporosis reports, vol. 16, no. 4, pp. 434-442, 2018.

[5] M. Bethel, B. R. Chitteti, E. F. Srour, and M. A. Kacena, "The changing balance between osteoblastogenesis and adipogenesis in aging and its impact on hematopoiesis," Current osteoporosis reports, vol. 11, no. 2, pp. 99-106, 2013.

[6] E. Özçivici, "Effects of spaceflight on cells of bone marrow origin," Turkish Journal of Hematology, vol. 30, no. 1, p. 1, 2013.

[7] N. G. Durmus et al., "Magnetic levitation of single cells," Proceedings of the National Academy of Sciences, vol. 112, no. 28, pp. E3661-8, Jul 14 2015, doi: 10.1073/pnas.1509250112.

[8] S. Yaman, M. Anil-Inevi, E. Ozcivici, and H. C. Tekin, "Magnetic Force-Based Microfluidic Techniques for Cellular and Tissue
Bioengineering," Front Bioeng Biotechnol, vol. 6, p. 192, 2018, doi: 10.3389/fbioe.2018.00192.

[9] M. Anil-Inevi et al., "Biofabrication of in situ Self Assembled 3D Cell Cultures in a Weightlessness Environment Generated using Magnetic Levitation," Sci Rep, vol. 8, no. 1, p. 7239, May 8 2018, doi: 10.1038/s41598-018-25718-9.

[10] F. Liu, K. Pawan, G. Zhang, and J. Zhe, "In situ single cell detection via microfluidic magnetic bead assay," PloS one, vol. 12, no. 2, p. e0172697, 2017.

[11] O. Baskan, G. Mese, and E. Ozcivici, "Low-intensity vibrations normalize adipogenesis-induced morphological and molecular changes of adult mesenchymal stem cells," Proceedings of the Institution of Mechanical Engineers, Part H: Journal of Engineering in Medicine, vol. 231, no. 2, pp. 160-168, 2017.

[12] O. Sarigil, M. Anil, E. Yilmaz, G. Mese, H. C. Tekin, and E. Ozcivici, "Label-free density-based detection of adipocytes of bone marrow origin using magnetic levitation," Analyst "in press", 2019. 